\title{
The Chemist, that Madman! How Children Perceive Science
}

\author{
Michela Luraschi, Riccardo Rezzonico, and Giovanni Pellegri*
}

\begin{abstract}
He is grown-up, not young, often bald, strictly male, often a chemist, wearing odd clothes and working on mysterious things, conducting projects which sometimes help save the world, sometimes harm our natural environment. He lives and works - often into the small hours - in a grey laboratory, alone, no colleagues, utterly isolated from the outside world. His 'space' looks like a laboratory equipped with test tubes, with reactive substances but also magic potions; mostly a windowless space, and any windows there are have iron bars. This is how, broadly speaking, and stereotypically, children see scientists. Chemistry and biology are the two most popular branches. Only rarely do we associate these images - which appear to be a simple figment of a child's imagination - to the problem of staff shortages in the 'MINT' sectors in Switzerland and to the shortfall in the number of women scientists. Nonetheless, some of the ideas presented in this article suggest that a child's outlook on science, fairly deep-rooted from as early as 9 or 10 years of age (and surprisingly unchanged by the time these kids reach secondary school) may have an impact on their future career choices. L'ideatorio, at Università della Svizzera italiana, is committed to counteracting this distorted view, in particular by creating particular spaces where children can meet science - not a 'crazy', but a normal and also female, science. In these spaces, chemistry is not synonymous with bad smells and pollution, but with benefits and discovery.
\end{abstract}

Keywords: Children and chemistry $\cdot$ Public perception of science $\cdot$ Science and society
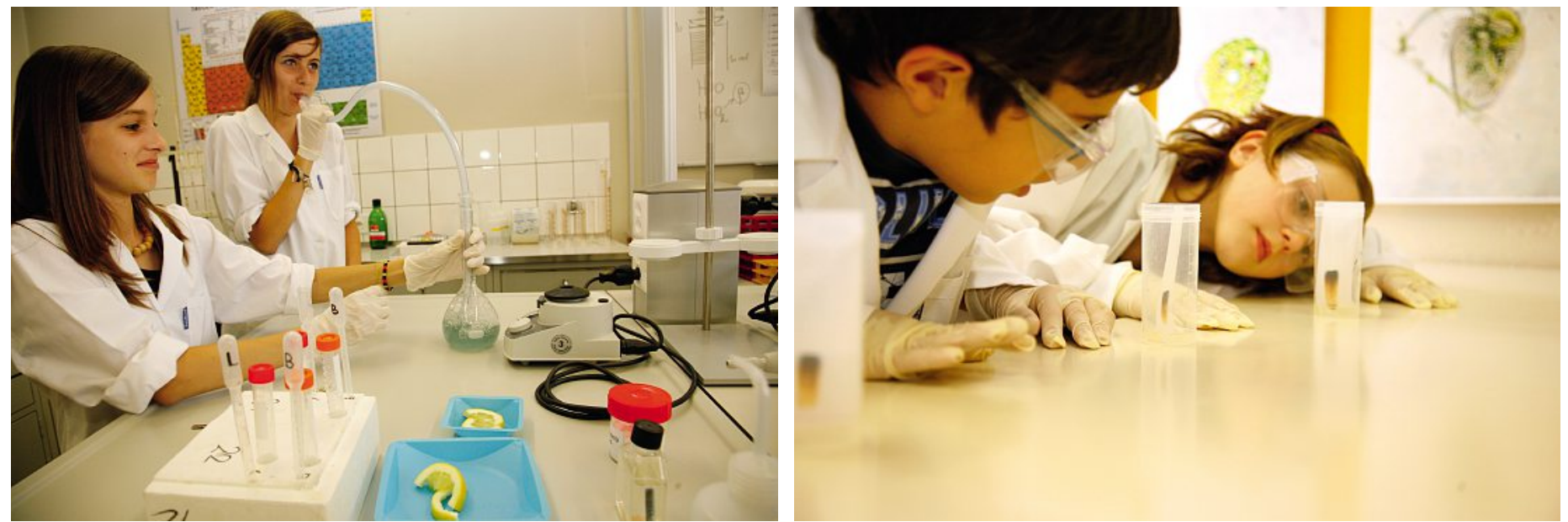

Fig. 1. BioLab, Lugano. 15-year-old students (left) and 9-year-old pupils (right) in action.

Over the last few years, L'ideatorio at Università della Svizzera italiana (Lugano) has worked on various projects designed to bring young people closer in touch with science. These projects include a chemistry and biology laboratory, known as 'BioLab', set up in conjunction with the School Authority of the City of Lugano,

${ }^{\star}$ Correspondence: Dr. G. Pellegri L'ideatorio

Università della Svizzera italiana

Via Lambertenghi $10 a$

$\mathrm{CH}-6900$ Lugano

Tel.: +4158666 4520

E-mail: giovanni.pellegri@usi.ch and sponsored by KGF (Contact Group for Research Matters) and Science et Cité, an expert centre of the Swiss Academy of Sciences (Fig. 1). The work of BioLab, like all work carried out as part of other projects of L'ideatorio, was originally sparked off by reflections over the way children and adults view science in our society. This article puts forward some theoretical considerations on the public perception of science and on research methods tested in an attempt to narrow, or close, the gap between science and society. This gap, or divide, has recently been denounced by the Federal Council, in a report on MINT (the acronym stands for: Mathematics, Informatics, Natural and Technical sciences). ${ }^{[1]}$

\section{The Situation in Switzerland}

Like all industrialised countries, Switzerland, too, is experiencing skilledlabour shortages in the MINT sectors. Surveys conducted in March 2009 show Switzerland faced with this situation: against 173,000 employees fully trained in the MINT sectors, there were 16,000 vacant positions and approximately 2,000 MINT graduates seeking employment. The chemical industry as well the life sciences also recorded slight difficulties: in the period surveyed, the market was seeking to fill 1,000 positions with specific skills in these sectors. To bring young people closer to science and technology, for some years now promotion campaigns have been or- 
ganised for boys and girls aged 16 to 19 . By the time they reach this age, however, the imagination of young people has already been set - the special field chosen at the age of 15 (in secondary school) will be decisive for the orientation of the academic or professional future. 18,000 certificates of secondary education were awarded in Switzerland in 2008. The specific strands favoured by students were modern languages $(25 \%)$ and economics and law (19\%). Two other strands, physics and applications to mathematics and biology and chemistry were chosen only by $10 \%$ and $16 \%$ of pupils respectively.[2] After that, $89 \%$ of A-level graduates enrol in higher education. At that point, available data show that those who studied physics and applications to mathematics will subsequently read mathematics or engineering at university, while those who opted for biology and chemistry will go on to read medicine or natural sciences. Taking the example of the Federal Institute of Technology, Lausanne: over $65 \%$ of its students came from the physics and applications to mathematics strand in upper secondary school. Finally, there is still a patent lack of interest among female students in some domains of science and technology: a mere $11 \%$ of people registered for a course of professional training in the MINT disciplines in 2006 were women. ${ }^{[2]}$ In technology, the percentage figure was as low as $6 \%$. In 2008, the proportion of women enrolled in a university or in a federal institute of technology was definitely lower than men's. When it comes to choosing a course of studies in tertiary education, women tend to choose other domains, especially teaching or the healthcare professions.

There are various reasons behind this skilled-staff shortages in the MINT sectors. In part, these have been analysed and listed by the Federal Council Report. It does in any case emerge that the profiles or special fields chosen in the first year of upper secondary school do prove a one-way track to a certain career destination. If we want to create the appropriate instruments to drive young people towards science, we should first initiate a dialogue with the younger age groups, namely the 5- to 14-years old. And the basic question we should ask is: where does our perception of science come from? When we pronounce the terms: 'science' and 'scientist', what model do we have in mind?

\section{Public Perception of Science}

As is well known, all our common perception of science grows out of the collective imagination, teeming with images, metaphors, analogies, and scientific references ${ }^{[3]}$ - but not only. Its stock is constantly fuelled by films, advertising, cartoons, and scientific dissemination, magnified and distorted by mass media; and strengthened, but also slightly changed, by our everyday interactions with school mates/work colleagues, friends, and family. What we are left with, in the end, is a series of simplifications which occur and recur in our common parlance: chemistry, for instance, is seen as something artificial, hazardous, which pollutes and generates diseases; it is diametrically opposed to characterisations such as natural and healthy. The scientist is often crazy, eccentric, weird, loopy, etc. he is in any case a man, who can either destroy or save our planet. These pictures are deep-rooted in our society; they materialise in films and in TV adverts. ${ }^{[4-7]}$ The distortions, however, should not be blamed on the mass media or the cinema. Imagination is also shaped by a set of symbols that are latent in all of us: and it measures up to its own fears, its hopes and beliefs. The undisputed benefits of a vaccine of proven effectiveness will always come up against the concerns caused by injecting an unknown serum into our bloodstream. The scientific knowledge displayed by the public can be little more than a fascinating tangle of prejudices, imagination, and true facts. ${ }^{[3,8,9]}$

\section{Please Draw a Science Laboratory}

In this context, let's place a blank sheet in front of a pupil and ask him to draw a laboratory (Fig. 2, Fig. 3). What will he/ she come up with? Several children did not stop at drawing the laboratory: they added a figure, someone working there. This immediately prompted a basic question: is the scientist male or female? Less than half $(47 \%)$ of the girls drew a woman scientist. None of their male counterparts drew a female scientist. For the young men, it is almost as if the feminine figure were banned from the research laboratory. In sum, $71 \%$
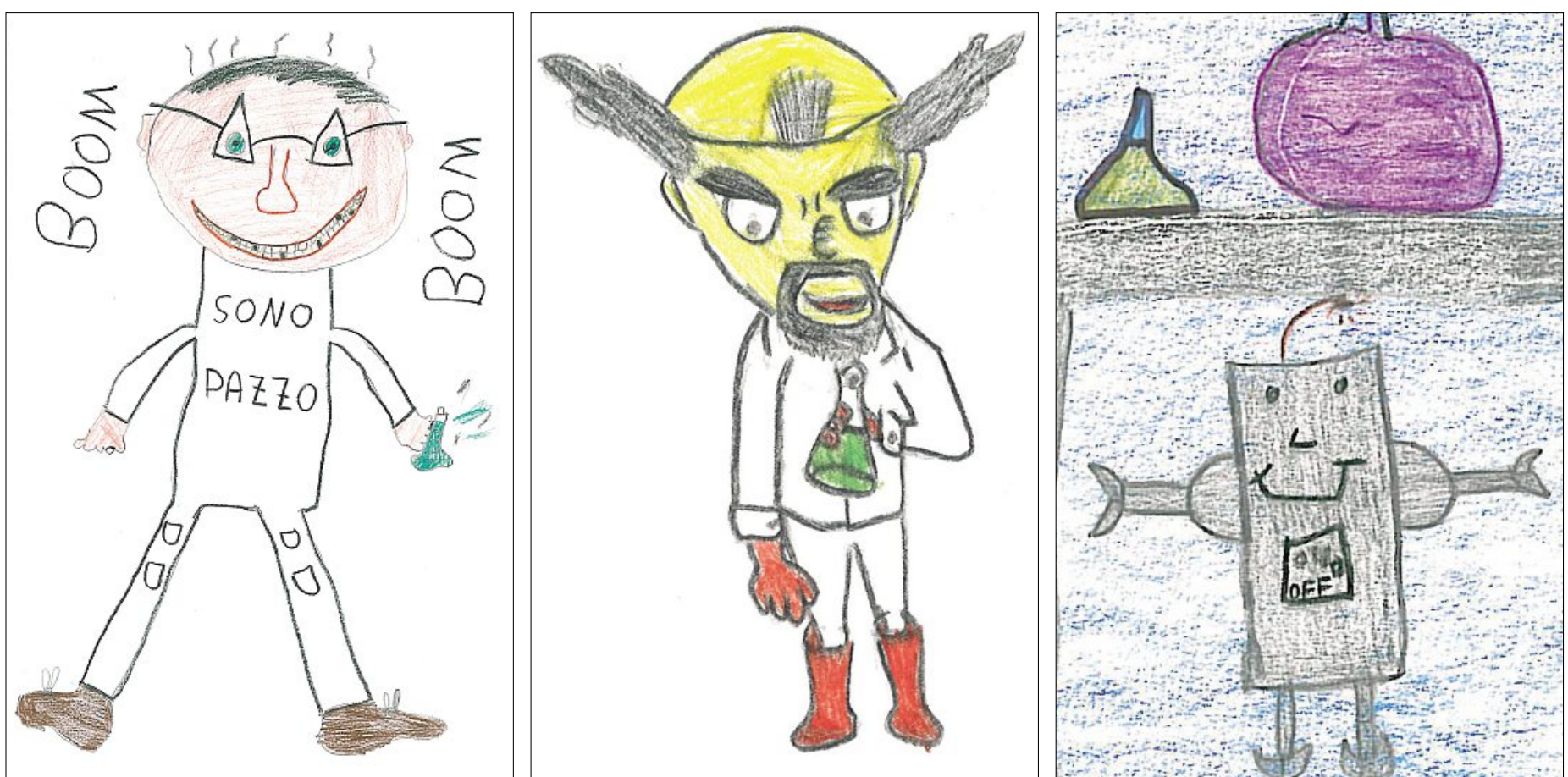

Fig. 2. The scientist as seen by kids. 'Scientists' as portrayed by primary-school children. Some remarkable features of a child's imagination include: male, usually specialists of chemistry/biology, scientists are often characterized as oddballs (mad, weird, and loners). Note: "Sono pazzo" (i.e. I'm mad) printed on the T-shirt in the left-hand drawing! 


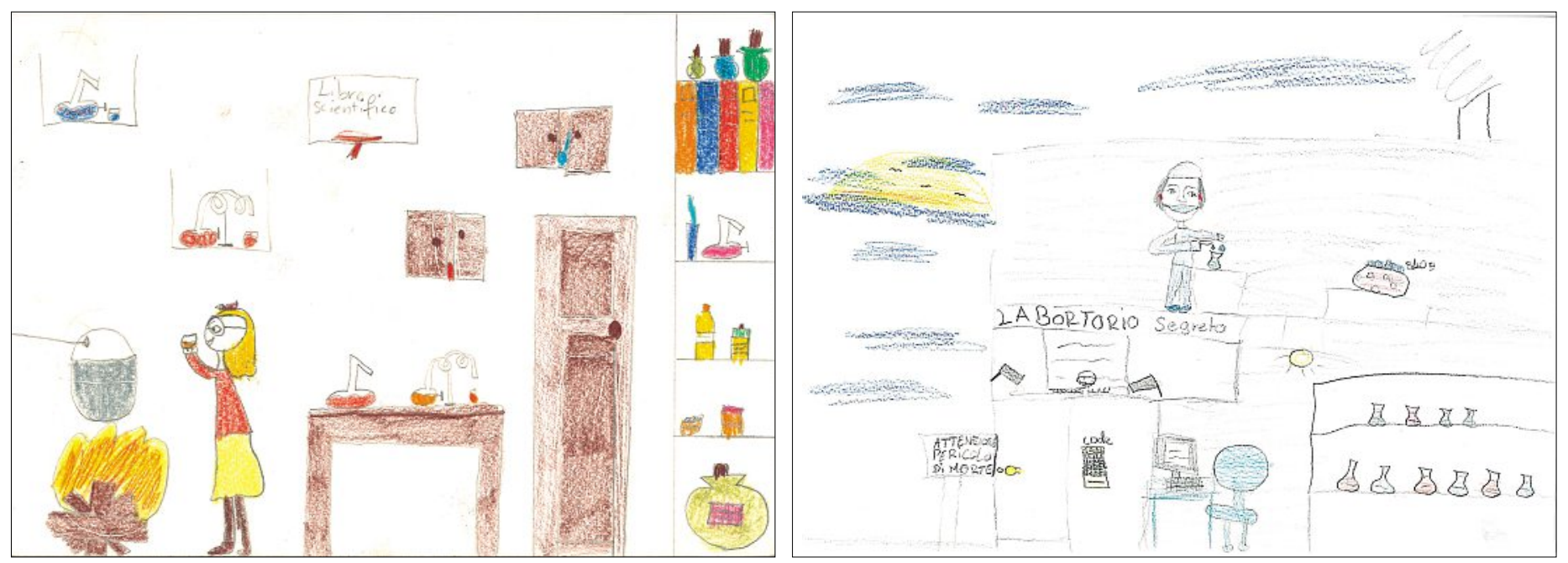

Fig. 3. The he-scientists as distinct from the she-scientist. A woman scientist's laboratory (to the left) and a man scientist's laboratory (to the right), as depicted by children.

of the primary school pupils we sampled (aged between 8 and 10) imagined a scientist as a man, and only the remaining $29 \%$ (all girls) believed that scientific research can also be carried out by women. In other cases, laboratories are seen as inhabited and operated by robots, or some futuristic creature, not by men or women.

Again, male and female scientists differ remarkably from each other. The man is a 'deviser', a bit whacky, white hair (or maybe blue?) sticking out at all angles, unconventional, surrounded by computers, formulae, robots, and concrete inventions. The woman looks rather tidier, cleaner, and elegant. The female scientist is portrayed as an ordinary person, dressed 'normally', with a neat haircut, who looks after her laboratory making sure that everything is in place. Unlike her male counterpart, a woman scientist seems to have scant creative genius. There are no machines around her, no computers, nor even any robots. She will have, however, test tubes, liquids, books, ... candles, and cauldrons! Magic or science? In a woman scientist's laboratory you will find brews of all kinds, but hardly anything related to engineering, informatics, or physics. The idea of a female scientist has far more connections with the world of medicine and biology, somewhat akin to that of sorcery. True, kids do think of science as of a world that is mostly male. When a woman joins in and becomes a legitimate member of the scientific community, then she will be good at looking after particular sectors, such as care/welfare, seeking solutions to issues related to helping her fellow human beings. The defining elements of a woman scientist, in other words, are socially-minded, aesthetic and well-groomed also when it comes to science: more than the male scientist, who, by contrast, comes dressed in a simple white lab coat, unfailingly wears glasses and looks as if he has just popped out of a car- toon. On this basis, faced with such dismal figures on 'MINT' staff shortages, it would be foolish not to take these representations seriously. Is it surprising that a school boy or girl, in the circumstances, may not wish to turn into this sort of person when they grow up? This is why it has become imperative, we feel, to review the common image of the scientist (whether male or female) and create a new one. Such a weird character - lonely and removed from reality! Even worse for girls, for whom the possibility does not even arise.

\section{Which Science?}

When we try to gauge what sort of science children picture in their minds, some major sectors seem to emerge: $61 \%$ of the children draw a biology or chemistry laboratory. Computer technologies seem to be included as well, though in rather a small proportion ( $25 \%$ of the drawings). The remaining drawings tend to separate between futuristic images (time-travel machines, machines for photocopying human beings) or mathematical formulae, physics equipment or installations, and astronomical instruments. The scientific disciplines thus pictured are neither unique nor specific: there may be a telescope in the scientist's laboratory, but equally and at the same time there may be test tubes and chemicals on the shelves. Here, too, there is an imagination fired by the figure of a multi-function scientist in pure Hollywood style, inspired by the Harry Potter novels and films, as well as by the image of Emmett Lathrop Brown, the mad scientist in 'Back to the Future'. These views are clearly in contrast with the real world of science, which has become increasingly specialised. In children's minds, a scientist's work is essentially to do with inventing: new potions, new machines to enlarge, reduce in size, or to photocopy human beings (Fig. 4).

\section{Where Does he Work?}

Scientists preferably work in a closed environment, discrete and protected, where one needs to tread carefully.

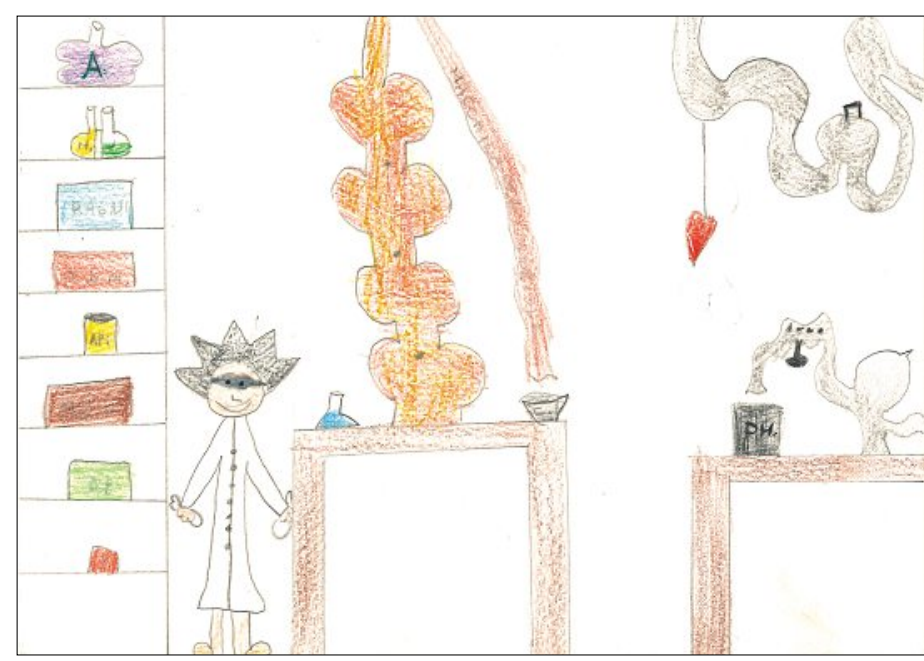

Fig. 4. 'Portrait' of a laboratory. Laboratories are mostly chemistry and/or biology laboratories. 

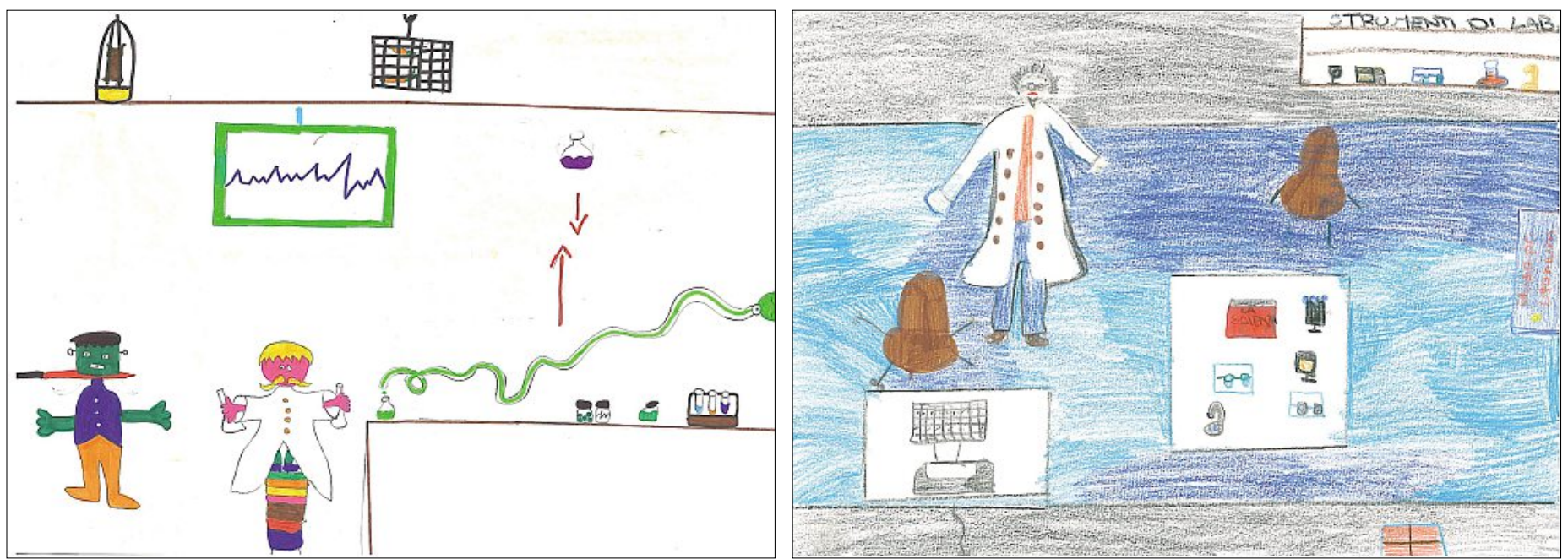

Fig. 5. Some features of a laboratory. Laboratories are often located underground, either with no windows, or with protective iron bars.

There are notices everywhere warning 'Do not touch', 'Health hazard', and pictures of skulls, explosives. In short, the scientist's home can also be full of risks, because new, mysterious tools are created there, so mysterious that there is no knowing what may happen. As a result, we come across secret doors and emergency exits: the scientist hides away, and there, in his underground lair, he is at work on his projects (Fig. 5). Thus, laboratories are lonely, isolated spaces: lifeless and often rather colourless. In a number of drawings, the kids have added security cameras and passwords. Only rarely can one spot laboratories that are open on the world: and if they are, it is through the lens of a telescope pointed at the sky, the stars and the planets; or also through special machines, set in a garden, ready to capture flashes of lightning, or God knows what other natural phenomenon or event. Scientists tend to work at night, amid candles and cobwebs, or surrounded by computers and calculators. They stand alone, slightly apart from the mass.

\section{Is Science Good or Bad?}

In the process of thinking about something, children (not unlike adults) consciously or unconsciously express an opinion. Because of this natural mechanism, in a child's drawings we will also catch an ethical dimension to the image of science. Primary school pupils tell us that scientists make use of their learning, their skills and notions to serve mankind: now saving the Universe, going into battle to keep off the enemy aliens, or construct machines to study and make sense of the sky, in an attempt to avert natural disasters. Many of the drawings convey with particular clarity that the purpose of science is to assure a safe future for mankind, and make the world better. In other words, science is positive in the eyes of children. It fulfils a purpose which is to help man and to unveil the secrets of the Universe. There are, on the other hand, aspects of science that can also be destructive, dangerous, and negative. The child may also picture in his head a dominant science, or a scientist able to conquer and rule the world, perhaps by pressing buttons, commanding hatches to fly open, everything being sucked up and away - or able to exercise control over all phenomena around us.

\section{Is it a Mere Figment of a Child's Imagination?}

These sketches are a mirror held up to a part of society. From early on, a child, steeped in his everyday life, conveys a view of science matching that of society as a whole. No wonder, then, if we ask secondary-school students (aged 17-18) to carry out the same task, the outcome closely resembles the stereotypes evinced in 10-year-old kids (Fig. 6). In $72 \%$ of the sketches drawn by upper-secondary students (boys and girls) the scientist is portrayed as male. In view of the changing roles of women and men in the scientific context, this rate is highly disappointing. The picture perfectly tallies with our observations of primary-school children. The women scientists depicted in $12 \%$ of sketches, here too, were nearly always drawn by female students $(75 \%)$. We also found gender-neutral scientists - according to the students' own definition (such scientists appear in $13 \%$ of the drawings) and, only in the tiniest proportion, laboratories inhabited by both male and female scientists $(3 \%)$. Bear in mind, also, that chemistry and biology stand out prominently among the various scientific disciplines drawn. A majority of the drawings (94\%) show a chemistry and biology laboratory. In a mere $6 \%$ of our samples does the emphasis fall on physics and mathematics. There are no examples of an IT laboratory making its way into the drawing of a primary-school kid or those of a secondaryschool student. Thus, it would seem that the imagination of a primary-school pupil is busier with technical disciplines than that of a secondary-school student.

As a matter of fact, a child's imagination is perfectly comparable, though more vague and caricatural, to the mind of an adult. Do grown-ups, too, conceive of a scientist as a male character, middle-aged, unkempt, working alone in a grey laboratory, often conducting experiments bordering on science fiction? Perhaps not so 'theatrically', but in the end there might not be such a big difference between the thought patterns of a child and those of an adult. The social representation of a scientist, of his role, of methods and findings is in actual fact shaped by the individual and collective beliefs inherent in society. In other words, if we ask a child to draw or tell us in words what science is, or what a scientist does, the resulting picture sums up all the features conveyed by the adults. The gender aspect is also produced by the culture we live in. The sketches are clear proof that gender differences are well rooted in girls and boys as young as ten. It is part of their awareness that science and technology are very largely a male preserve. It could hardly be otherwise, since all the messages that get through to our children confirm this stereotype: the scientist in cartoons and in films is male. This fact is further corroborated by puppets, pictures, and games - all of which offer young girls precious little chance of dreaming up a brilliant future as astronauts. These aspects are mirrored in the division of labour according to genderbased criteria (a mentality permeating cultures across borders). It is a state of affairs 

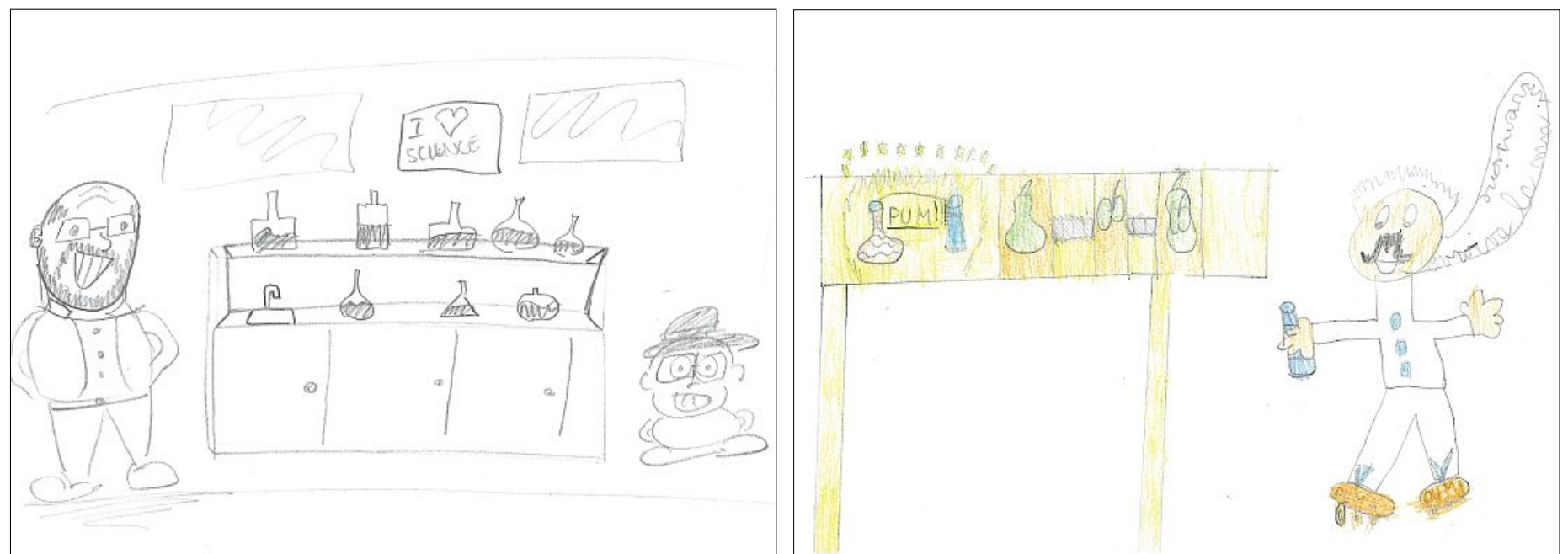

Fig. 6. Comparing the sketches of secondary-school (left) students with those of primary-school pupils (right). The scientist most secondary school students depict has the features of their biology, chemistry, physics or maths teacher.

that also affects the gap in registration figures for Science Faculties in universities: women who choose a science degree tend to study biology or medicine. Women are much less inclined, on the other hand, to go for technical subjects such as engineering. The mental representations taking shape in a primary school child may therefore be crucial for their future career choices; they are no less critical for a general concept of society as it takes shape. Children are a natural mirror reflecting our world: with their crayons they represent what we are.

We can detect another significant element in these sketches, namely the major role played by science teachers in the process of building up the image of a scientist in the student's mind. Quite frequently, the scientists sketched by grammar-school students depict their real-life teachers (this is what they claim) and the laboratory is indeed that of their school. More particularly, those few grammar-school boys who sketched a female scientist at work in a laboratory, had actually used their chemistry or biology teacher as a model.

These observations bear out the major role played by secondary-school teachers; ${ }^{[10]}$ for these students, teachers significantly become vectors of an image of the scientific world.

\section{About BioLab}

For some years now, L'ideatorio has created, across Ticino, some dedicated venues where children can meet science (Fig. 7). By applying the chosen methodology interactive learning - L'ideatorio provides a forum where young people can build up a knowledge of their own, based on the interaction between the subject and personal experience. At the heart of this process there are no notions or data to transfer, but a relation of exchange and experiences which is powered by the presence of a group leader. BioLab is one of these venues, an authentic laboratory of chemistry and biology where one can touch, experiment, put forward hypotheses, and undertake little research projects. The teaching components that we are more interested in are not the classic ones (what is an acid; definition of a solution; basic reaction from producing a 'salt'; the properties of water, etc.). We are much more keen on modules that help us develop scientific thought independently of notions. For instance, in the course of a module the task is to find out the composition of three mysterious liquids; and that can be done using any of the tools available in the laboratory. In this way, the child is free to frame hypotheses; then conduct experiments, and finally confirm or deny his/ her initial hypotheses.

\section{L'ideatorio: Questions and Implications}

Having described and analysed our findings on the public perception of science, we wish to submit the following essential points:

1. The role of the group leader. Children are far more fascinated by a story narrated by somebody than by data found in a book. A child is captivated by a woman or a man who has studied and specialised in chemistry, not by the glucose formula. A good group leader, therefore, must be a
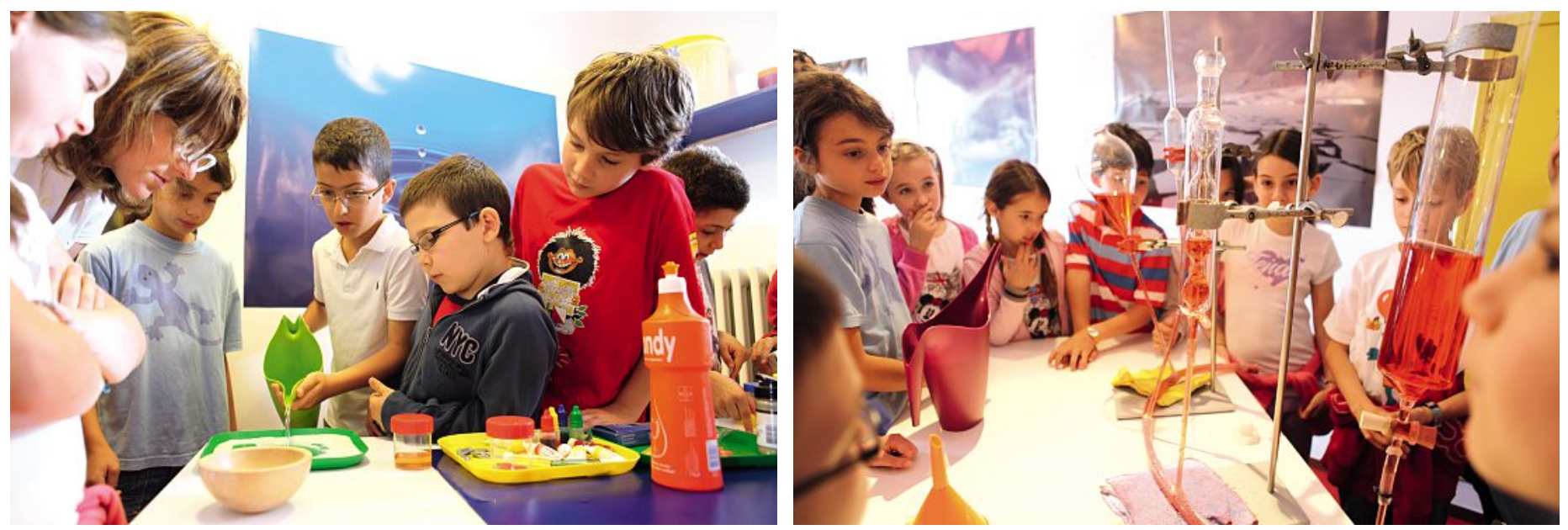

Fig. 7. Making science 'normal' through interactive projects. Some children at work on L'ideatorio projects. 
person who can listen and enliven a dialogue, conveying passion and joy, and not merely his/her knowledge of a subject. But the laboratory must not turn into a playground either. Together, we will discover that we can have fun even when dealing with serious matters.

2. Fighting against the idea of a mad scientist. In order to win over children to science, many projects put forward the figure of the scientist as a clown, or as a mad chemist, who draws attention to himself by his sartorial style, his explosive reactions, and his hair. This method, much bandied about in several science festivals, is hardly likely to entice children to real science; it is bound to reinforce the warped images already present in children.

3. Convey a female vision of science, by emphasizing the role that girls will be able to play in the world of science; and, secondly, by appointing women as group leaders and contact persons.

4. Emphasize the elements of wonder and discovery. The informal science of BioLab is not supposed to cram the head of pupils full of notions; it must first and foremost surprise and intrigue. If interest sparks off, then school will provide the necessary notions to learn about chemistry.

Through its various projects, L'ideatorio meets 10,000 young people every year. It is hard to predict whether these activities will deliver a better perception of science in children. As for us, we like quoting those little girls who, on leaving BioLab, declare with shining eyes: "Before coming here, I thought I was going to become a hairdresser; but now I want to be a scientist". No doubt that sounds rather like a starry-eyed remark after the enthusiasm derived from the moments spent together. Yet, it will certainly influence that pre-existent store of images of a 'weird, male, and lonely science'. Our objective is not to convince young people that science is the safe and secure path for their lives. However, regardless of the trade or profession they are going to end up working in, we believe that a positive, though critical, eye on science will be infinitely better than an unreal and eccentric caricature.

Received: July 8, 2012
[1] 'Mangel an MINT-Fachkräften in der Schweiz: Ausmass und Ursachen des Fachkräftemangels in MINT (Mathematik, Informatik, Naturwissenschaften und Technik)', Bericht des Bundesrates, August 2010.

[2] E. Ramseier, J. Allraum, U. Stalder, F. Grin R. Alliata, S. Müller, I. Willimann, E. Dozio, P. Labudde, K. Maag Merki, E. Pagnossin, E. Stocker, E. Berger, L. Tozzini Paglia, D. Sartori, 'Evaluation der Maturitätsreform 1995 (EVAMAR I). Neue Fächerstruktur, pädagogische Ziele, Schulentwicklung. Schlussbericht zur Phase I', SER, Bern, 2005.

[3] J. R. Durant, G. A. Evans, G. P. Thomas, Nature 1989, 340, 11 .

[4] C. R. Barman, J. Science Teacher Education 1999, 10,43

[5] D. Fort, V. Heather, Science \& Children 1989, 26,8 .

[6] R. Silve. J. American Art Therapy Association 1992, $9,85$.

[7] E. Flicker, Public Understanding of Science 2003, 12, 307.

[8] J. R. Durant, 'Two cultures of public understanding of science and technology in Europe', in 'Between Understanding and Trust: The Public, Science and Technology', Eds. M. Dierkes, C. von Grote, Amsterdam: Harwood Academic Publishers, 2000, pp. 131-156.

[9] E. Einsiedel, 'Understanding 'publics' in the public understanding of science', in 'Between Understanding and Trust: The Public, Science and Technology', Eds. M. Dierkes, C. von Grote, Amsterdam: Harwood Academic Publishers, 2000.

[10] E. Poglia, C. Molo, Schweizerische Zeitschrift für Bildungswissenschaften 2007, 29. 